\title{
Interference of Neodymium with the Antioxidative Defense Mechanisms of Jerusalem Artichoke (Helianthus tuberosus) Seedlings Grown under Cadmium Stress
}

\author{
Zhihong Tang ${ }^{1 * \dagger}$, Wenjun $\mathrm{Li}^{2 \dagger}$, Shao Hong Wen ${ }^{1}$, Ru Hong Ren ${ }^{1}$, Zhengyi Liu ${ }^{2}$ and Song Qin ${ }^{2 *}$ \\ ${ }^{1}$ College of Life Science, Yantai University, Yantai 264005, China \\ ${ }^{2}$ Yantai Institute of Coastal Zone Research, Chinese Academy of Sciences, Yantai 264003, China \\ *For correspondence: tangzhihong7405@163.com; sqin@yic.ac.cn \\ ${ }^{\dagger}$ Co-first authors
}

\begin{abstract}
Cadmium $(\mathrm{Cd})$ is a serious environmental pollutant constraint to plant production in some regions. As an important rare earth element (REE), neodymium (Nd) plays a positive role in plant growth. However, few researches have reported the effect of $\mathrm{Nd}$ on $\mathrm{Cd}$ toxicity. Thus, our study was to investigate the role of $\mathrm{Nd}$ in alleviating of Cd toxicity induced stress. Our results showed that $\mathrm{CdCl}_{2}$ addition significantly inhibited the growth of Jerusalem artichoke (Helianthus tuberosus L.) seedlings, while the inhibition was improved by $\mathrm{NdCl}_{3}(10 \mu M$ and $20 \mu M) . \mathrm{CdCl}_{2}$ treatment also increased reactive oxygen species (ROS) and lipid peroxidation measured as malondialdehyde (MDA) concentration and decreased the activities of the antioxidant enzymes. However, $\mathrm{NdCl}_{3}(10 \mu M$ and $20 \mu M)$ could significantly alleviate oxidative damage and increased the activities of antioxidant enzymes in Jerusalem artichoke seedlings exposed to Cd stress. The result suggested that appropriate concentration of $\mathrm{NdCl}_{3}$ could effectively alleviate $\mathrm{Cd}$ toxicity is partly related to decreasing oxidative stress and an increase in antioxidant enzyme in H. tuberosus seedlings. (C) 2017 Friends Science Publishers
\end{abstract}

Keywords: Antioxidant enzymes; Cadmium stress; Helianthus tuberosus L; Neodymium

\section{Introduction}

Cadmium $(\mathrm{Cd})$ is one of the most toxic heavy metals to plants and has become a serious environmental contaminant due to the use of $\mathrm{Cd}$ in various anthropogenic activities such as metalworking industries, power stations and waste incinerators. $\mathrm{Cd}$ is easily taken up by roots and transported to other parts of the plant being toxic to living cells at very low concentrations (Gallego et al., 2012; Zafar and Javed, 2016). Recent studies have shown that Cd can cause adverse effects on some physiological and biochemical process such as photosynthesis, energy production, lipid metabolism and water relations, thereby leading to diminished plant biomass and economic yield (Sanita and Gabbrielli, 1999; Ali et al., 2011; Atta Ullah et al., 2016). The toxic effect of $\mathrm{Cd}$ on plants is partly related to the increase of reactive oxygen species (ROS) including superoxide radicals $\left(\mathrm{O}_{2} \cdot{ }^{-}\right)$, hydrogen peroxide $\left(\mathrm{H}_{2} \mathrm{O}_{2}\right)$ and hydroxyl radical $(\cdot \mathrm{OH})$ (Zhang et al., 2009; Gill and Tuteja, 2010; Hussain et al. 2017). Plants affected by ROS are extremely harmful to proteins, lipids and nucleic acids and bring about their oxidation (Pandey et al., 2005). To alleviate oxidative injury plants have developed an antioxidative system through enhancing antioxidant enzyme activities and antioxidants synthesis (Qiu et al., 2013; Gowayed et al., 2017).
Rare earth elements (REEs) are a special class of metal elements. In recent years, the effects of REEs on physiological responses have been reported in different kinds of plants (Zhang and Chen, 2007; Wang et al., 2011). Previous studies have shown that neodymium $(\mathrm{Nd})$, an important light REEs can increase chlorophyll content and photosynthetic rate and stimulate the growth of plant at proper concentrations. Moreover, an appropriate amount of $\mathrm{Nd}$ could increase activities of the antioxidative defense system in some plants (Peng et al., 2013). However, currently few studies have focused on whether $\mathrm{Nd}$ can relieve oxidative damage in plants under environmental stresses.

Jerusalem artichoke (Helianthus tuberosus L.) is a $\mathrm{C}_{3}$ warm-season plant easily grown in semiarid and coastal areas. It is an economically-important crop species, which is used as food for human consumption, forage and feed for animal (Long et al., 2008; Huang et al., 2012). In recent years, it has been recognized that Jerusalem artichoke is a good source of inuline and fructose and therefore, it has potential applications in a wide variety of industries (Kosaric et al., 1984). Previous research has indicated that a high oxidative damage and inhibited antioxidant defense systems of Jerusalem artichoke grown under Cd stress (Tao et al., 2007). Up to now, there is no information known

To cite this paper: Tang, Z., W. Li, S.H. Wen, R.H. Ren, Z. Liu and S. Qin, 2017. Interference of neodymium with the antioxidative defense mechanisms of Jerusalem artichoke (Helianthus tuberosus) seedlings grown under cadmium stress. Int. J. Agric. Biol. 19: 906-910 
about the effect of $\mathrm{Nd}$ on the oxidative damage in this plant. In the present study, the influence of $\mathrm{Nd}$ on the growth and antioxidative defense system in Jerusalem artichoke seedlings under $\mathrm{Cd}$ stress was investigated. The aim of this research was to provide a certain reference for understanding the potential mechanism of $\mathrm{Nd}$ alleviating damage of Cd stress to plant.

\section{Materials and Methods}

\section{Plants and Treatments}

Jerusalem artichoke (Helianthus tuberosus L.) tubers were collected from Yantai of Shandong province, China. Tubers were cut into small square pieces, sterilized with $75 \%$ ethanol (v/v) for $30 \mathrm{~min}$ and rinsed drastically with distilled water. Subsequently, tuber slices with buds of Jerusalem artichoke were sprouted in plastic containers covered with 20-mesh quartz sand. Each container culured a single plant and was watered with nutrient solution once a day. The nutrient solutions were prepare as follows $(\mathrm{m} M): \mathrm{H}_{3} \mathrm{BO}_{3}$, 1.25; $\mathrm{Ca}\left(\mathrm{NO}_{3}\right)_{2}, 0.5 ; \mathrm{KNO}_{3}, 0.5 ; \mathrm{MgSO}_{4}, 0.017 ; \mathrm{MnSO}_{4}$, $0.1 ; \mathrm{NiSO}_{4}, 0.04 ; \mathrm{K}_{2} \mathrm{SO}_{4}, 0.034 ; \mathrm{CuSO}_{4}, 0.025 ; \mathrm{Na}_{2} \mathrm{MoO}_{4}$, 0.025; $\mathrm{ZnSO}_{4}, 0.025$; and Fe-EDTA , 10 (Wang et al., 2009; Wang et al., 2011). The nutrient solution was replaced every two days. After 15 days, uniform size seedlings with one expanding leaf and three fully extended leaves were planted into plastic pots containing quartz sand (each pot contained three plant)) (Monti et al., 2005; Xue and Liu, 2008).

Five days later, $\mathrm{CdCl}_{2}$ and $\mathrm{NdCl}_{3}$ were added into nutrient solution making 5 treatments: (1) control (CK), (2) $100 \mu M \mathrm{CdCl}_{2}$ alone (Cd), (3) $5 \mu M \mathrm{NdCl}_{3}+100 \mu M$ $\mathrm{CdCl}_{2}(5 \mu M)$, (3) $10 \mu M \mathrm{NdCl}_{3}+100 \mu M \mathrm{CdCl}_{2}(10 \mu M)$, (4) $20 \mu M \mathrm{NdCl}_{3}+100 \mu M \mathrm{CdCl}_{2}(20 \mu M)$ and (5) $50 \mu M$ $\mathrm{NdCl}_{3}+100 \mu M \mathrm{CdCl}_{2}(50 \mu M)$. The treatment of concentrations was according previous research, in which a number of higher and lower levels of $\mathrm{Cd}$ were applied. Care was taken to enture that each container received the same volume of the planned solution for every treatment and that there was no water stress. All treatments were carried out in triple. The experiment repeated three times. After 15 days of treatment plants were harvested for biochemical and physiological assay.

\section{Plant Growth Measurement}

At harvest, the height of the plants was recorded. Then the plants were partitioned into root, stem and leaves. The dry weight (DW) of root, stem and leaves was determined by drying a known fresh weight of homogenized samples at $60^{\circ} \mathrm{C}$ until constant weights were obtained.

\section{Assay of $\mathrm{H}_{2} \mathrm{O}_{2}, \mathrm{O}_{2}^{-}$and MDA Levels and SOD, POD and CAT Activities}

Leaves collected from plants grown under various conditions were homogenized in cold phosphate buffer (50 $\mathrm{m} M, \mathrm{pH} 7.8)$ containing $1 \%(\mathrm{v} / \mathrm{v})$ polyvinylpyrrolidone, 5 $\mathrm{m} M$ ethylenediaminetetraacetic acid and $5 \mathrm{~m} M$ dithiothreitol. The homogenates were centrifuged at 15,000 rpm for $15 \mathrm{~min}$ at $4^{\circ} \mathrm{C}$ and the supernatant was applied to the analysises of $\mathrm{O}_{2} \cdot{ }^{-}, \mathrm{H}_{2} \mathrm{O}_{2}$ and MDA levels and antioxidant enzyme activities.

Content of $\mathrm{O}_{2} .^{-}$was determined at $530 \mathrm{~nm}$ by monitoring the nitrite formation from hydroxylamine in the presence of $\mathrm{O}_{2} \cdot^{-}$(Elstner and Heupel, 1976). $\mathrm{H}_{2} \mathrm{O}_{2}$ content was measured at $390 \mathrm{~nm}$ (Wang et al., 2009). Lipid peroxidation was assayed by measuring MDA content using the thiobarbituric acid (TBA) reaction and the absorbance was measured at 532 and $600 \mathrm{~nm}$ to calculate MDA concentration (Buege and Aust, 1978).

Superoxide dismutase (SOD) activity was assayed by measuring the inhibition in photochemical reduction of nitroblue tetrazolium (NBT) (Beauchamp and Fridovich, 1971). The reaction mixture $(3.0 \mathrm{~mL})$ included $20 \mathrm{~m} M$ phosphate buffer, $13 \mathrm{~m} M$ methionine, $2 \mu M \mu$ riboflavin, 75 $\mu M$ NBT, $10 \mu M$ EDTA and $0.05 \mathrm{~mL}$ enzyme extract. The tubes was illuminated with two $20 \mathrm{~W}$ fluorescent for $20 \mathrm{~min}$ to initiate the reaction. The absorbance of the reaction mixture was read at $560 \mathrm{~nm}$. One unit of SOD activity represented the amount of enzyme required to cause $50 \%$ inhibition the NBT photoreduction rate.

Catalase (CAT) activity was determined based on the procedures described by Durner and Klessing (1996). The reaction mixture $(3.0 \mathrm{~mL})$ contained $50 \mathrm{~m} M$ phosphate

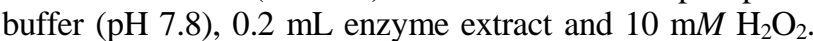
The absorbance was read at $240 \mathrm{~nm}$. $1 \mu M \quad \mathrm{H}_{2} \mathrm{O}_{2}$ decomposed in 1 min represented one unit (U) of CAT.

Peroxidase (POD) activity was determined based on the method of Hammerschmidt et al. (1982). $2.9 \mathrm{~mL}$ of 100 $\mathrm{m} M$ phosphate buffer ( $\mathrm{pH} 7.0)$ containing guaiacol $(0.05 \%)$ and $10 \mathrm{~m} M \mathrm{H}_{2} \mathrm{O}_{2}$ was mixed with $0.1 \mathrm{~mL}$ of enzyme extract. Activity was determined by the increase per minute in the absorbance at $470 \mathrm{~nm}$. One unit of peroxidase activity was equated to an increase of 0.01 absorbance units per minute.

\section{Statistical Analysis}

Each treatment was repeated three times. All measured data were expressed as mean \pm SD deviation. SPSS software (SPSS Inc., version 11.5, Chicago, USA) was used to perform statistical analysis. Differences between comparisons with $P<0.05$ were considered as statistical significance.

\section{Results}

\section{Plant Growth of Jerusalem artichoke}

Table 1 shows the plant height and dry weight of different organs of Jerusalem artichoke seedlings under various 
Table 1: Effect of $\mathrm{NdCl}_{3}$ and $\mathrm{CdCl}_{2}$ on growth indexes of H. tuberosus

\begin{tabular}{lllll}
\hline Treatment & Plant height $(\mathrm{cm})$ & \multicolumn{3}{c}{ Dry weight (g/plant) } \\
\cline { 3 - 5 } & & Leaves & Stems & Roots \\
& & $0.87 \pm 0.11 \mathrm{a}$ & $1.09 \pm 0.11 \mathrm{a}$ & $0.36 \pm 0.05 \mathrm{a}$ \\
$\mathrm{CK}$ & $21.36 \pm 1.84 \mathrm{a}$ & $0.38 \pm 0.05 \mathrm{c}$ & $0.61 \pm 0.07 \mathrm{c}$ & $0.19 \pm 0.02 \mathrm{c}$ \\
$\mathrm{Cd}$ & $10.23 \pm 1.27 \mathrm{c}$ & $0.050 .05 \mathrm{c}$ & $0.20 \pm 0.03 \mathrm{c}$ \\
$\mathrm{Nd} 5$ & $12.17 \pm 1.05 \mathrm{c}$ & $0.41 \pm 0.06 \mathrm{c}$ & $0.67 \pm 0.05 \mathrm{c}$ & 0.05 \\
$\mathrm{Nd} 10$ & $15.23 \pm 1.96 \mathrm{~b}$ & $0.67 \pm 0.10 \mathrm{a}$ & $0.85 \pm 0.06 \mathrm{~b}$ & $0.32 \pm 0.05 \mathrm{~b}$ \\
$\mathrm{Nd} 20$ & $16.41 \pm 2.12 \mathrm{ab}$ & $0.62 \pm 0.11 \mathrm{~b}$ & $0.98 \pm 0.09 \mathrm{ab}$ & $0.28 \pm 0.06 \mathrm{~b}$ \\
$\mathrm{Nd} 50$ & $9.83 \pm 1.17 \mathrm{~d}$ & $0.32 \pm 0.08 \mathrm{~d}$ & $0.62 \pm 0.08 \mathrm{~d}$ & $0.15 \pm 0.02 \mathrm{~d}$ \\
\hline Each value represents the mean $\pm \mathrm{SD}, \mathrm{n}=3$. & Different letters in each \\
column indicate significant difference at $P<0.05$
\end{tabular}

conditions. The plant height and dry weight of leaves, stems and roots in $100 \mu M \mathrm{CdCl}_{2}$ treatment group were significantly decreased $(P<0.05)$ when compared with those of the control group. The application of $5 \mu M \mathrm{NdCl}_{3}$ seemed to be no notable effects on the the plant growth compared to $100 \mu M \mathrm{CdCl}_{2}$ treatment groups. However, treatment with $10 \mu M$ and $20 \mu \mathrm{M}$ neodymium significantly alleviated $(P<0.05) \mathrm{CdCl}_{2}$ induced inhibition of growth. $10 \mu M \mathrm{NdCl}_{3}$ had the best effect on the dry weight of leaves and roots and they were increased by 76.32 and $68.42 \%$, respectively as compared with $100 \mu M \mathrm{CdCl}_{2}$ treatment groups. In $20 \mu M$ neodymium treatment group, plant height and dry weight of stems increased by 62.66 and $60.65 \%$ as compared with 100 $\mu M \mathrm{CdCl}_{2}$-treatment group. However, the application of 50 $\mu \mathrm{M}$ neodymium resulted in a negative effect the growth of Jerusalem artichoke seedlings.

\section{ROS Accumulation and Lipid Peroxide Level}

The contents of $\mathrm{O}_{2}{ }^{-}, \mathrm{H}_{2} \mathrm{O}_{2}$ and MDA in Jerusalem artichoke seedlings under various conditions are shown in Fig. 1. The contents of $\mathrm{O}_{2} \cdot{ }^{-}, \mathrm{H}_{2} \mathrm{O}_{2}$ and MDA in $100 \mu M \mathrm{CdCl}_{2}$ treatment group were significantly increased $(P<0.05)$ as compared with those of the control. In $5 \mu M \mathrm{NdCl}_{3}$ treatment groups, the contents of $\mathrm{O}_{2}{ }^{-}, \mathrm{H}_{2} \mathrm{O}_{2}$ and MDA was slightly decreased $(P>0.05)$ compared with $100 \mu M \mathrm{CdCl}_{2}$ treatment groups. Nevertheless, Application of $10 \mu M$ and $20 \mu M \mathrm{NdCl}_{3}$ significantly reduced $(P<0.05)$ the contents of $\mathrm{O}_{2}{ }^{-}, \mathrm{H}_{2} \mathrm{O}_{2}$ and MDA. At the same $\mathrm{CdCl}_{2}$ concentration, application of $10 \mu M \mathrm{NdCl}_{3}$ reduced the seedling contents of $\mathrm{O}_{2}{ }^{-}, \mathrm{H}_{2} \mathrm{O}_{2}$ and MDA by $23.89,33.83$ and $31.52 \%$, respectively. In $20 \mu M \mathrm{NdCl}_{3}$ treatment groups, the contents of $\mathrm{O}_{2}{ }^{-}, \mathrm{H}_{2} \mathrm{O}_{2}$ and MDA decreased by $11.94,35.71$ and $29.15 \%$, respectively as compared with $100 \mu M \mathrm{CdCl}_{2}$ treatment groups. In contrast, application of high concentration of $\mathrm{NdCl}_{3}(50 \mu M)$ notably increased the contents of $\mathrm{H}_{2} \mathrm{O}_{2}, \mathrm{O}_{2} .^{-}$and MDA of the seedlings.

\section{Antioxidant Defense}

The analysis of SOD, POD and CAT enzymes activities in different treatments is presented in Fig. 2. The plants exposed to $100 \mu M \mathrm{CdCl}_{2}$ appeared significant decrease $(P<0.05)$ in SOD activity versus the control. $\mathrm{NdCl}_{3}$ was

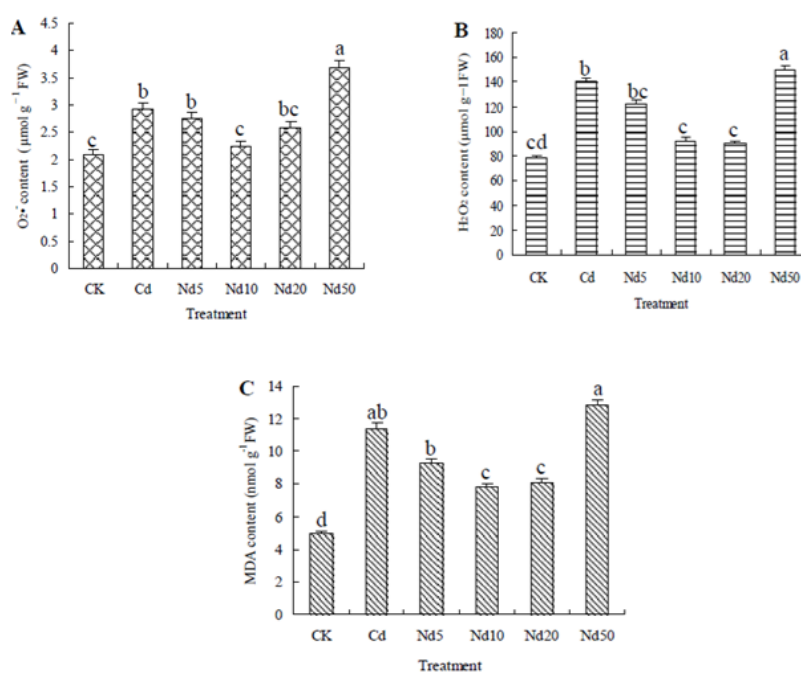

Fig. 1: Effect of $\mathrm{NdCl}_{3}$ and $\mathrm{CdCl}_{2}$ on $\mathrm{H}_{2} \mathrm{O}_{2}(\mathrm{~A}), \mathrm{O}_{2}{ }^{-}$(B), and $\mathrm{MDA}(\mathrm{C})$ content in $H$. tuberosus

Each value represents the mean $\pm S D, n=3$. Different letters within each graph indicate statistically significant differences at $P<0.05$
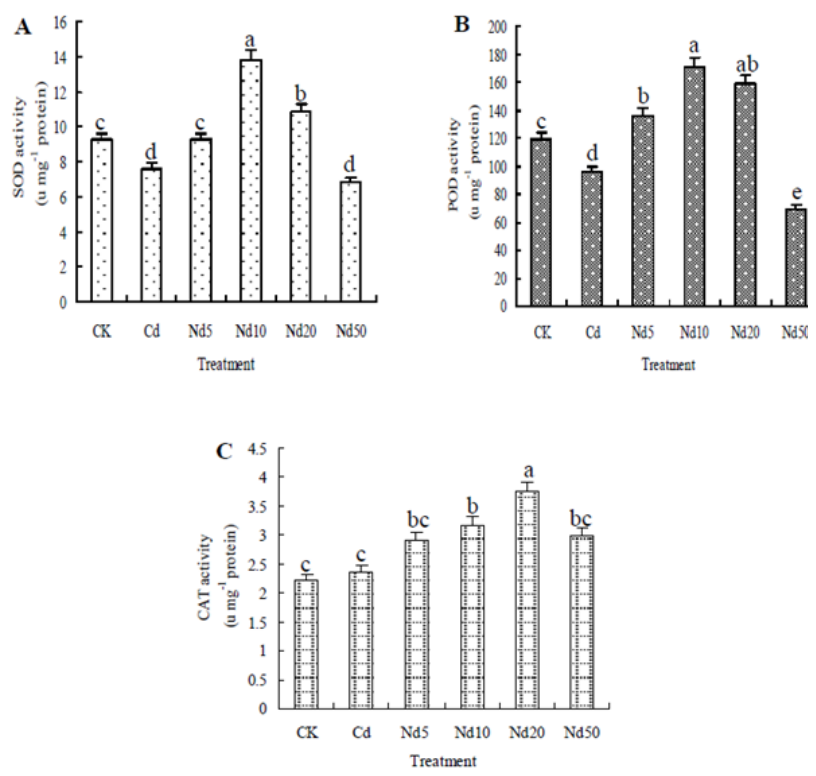

Fig. 2: Effect of $\mathrm{NdCl}_{3}$ and $\mathrm{CdCl}_{2}$ on $\mathrm{SOD}(\mathrm{A}), \mathrm{POD}(\mathrm{B})$, and CAT (C) activities of $H$. tuberosus

Each value represents the mean $\pm S D, n=3$. Different letters within each graph indicate statistically significant differences at $P<0.05$

effective in alleviating Cd inhibited SOD activity, especially at $10 \mu M$ and $20 \mu M$. Application of $10 \mu M$ and $20 \mu M$ $\mathrm{NdCl}_{3}$ significantly increased the activities of SOD by 82.19 and $43.67 \%$, respectively relative to $\mathrm{Cd}$ stressed plants. In terms of POD activity, $\mathrm{CdCl}_{2}$ treatment alone could not exert a remarkable effect on POD activity against that of the control. A little increase of POD activity was observed as the plants were treated with $5 \mu M \mathrm{NdCl}_{3}$ and the enhancement of POD in $10 \mu M$ and $20 \mu M \mathrm{NdCl}_{3}$ treatment 
groups was significant $(P<0.05)$. However, application of high concentration of $\mathrm{NdCl}_{3}(50 \mu M)$ significantly decreased $(P<0.05)$ POD activity compared with $100 \mu M \mathrm{CdCl}_{2}$ treatment groups. No obvious effects on CAT activity were observed in $\mathrm{CdCl}_{2}$ treatment groups, whereas different $\mathrm{NdCl}_{3}$ concentrations significantly increased $(P<0.05)$ CAT activity compared with the seedling under control and $\mathrm{CdCl}_{2}$ treatments. The $20 \mu M \mathrm{NdCl}_{3}$ had the most prominent effect on CAT activity, which was increased by $82.04 \%$ as compared with $100 \mu M \mathrm{CdCl}_{2}$ treatment groups.

\section{Discussion}

The growth inhibition is a response of plants exposure to toxic concentrations of $\mathrm{Cd}$ (Wang et al., 2007; Gallego et al., 2012). Our study revealed that treatment with $\mathrm{CdCl}_{2}$ $(100 \mu M)$ significantly reduced $(P<0.05)$ the plant height, fresh weight and dry weight of Jerusalem artichoke seedlings. Previous studies have found that the plant growth was suppressed by $\mathrm{Cd}$ owing to interfering in a range of metabolic processes, i.e., damage to photosynthetic machinery, decline in root elongation and inhibition of proton pump (Basharat et al., 2014). The results from the present study indicate treatment with appropriate concentration $\mathrm{NdCl}_{3}$ could significantly improved $(P<0.05)$ the growth of seedlings grown under $\mathrm{Cd}$ stress. It has been reported that suitable concentration $\mathrm{NdCl}_{3}$ can promote the cell proliferation and increases chlorophyll content in plant (Wang et al., 2011; Peng et al., 2013). We speculate that $\mathrm{NdCl}_{3}$ enhances the photosynthesis and induces the cell proliferation might be associated with its effect on growth of plants in the present stress conditions.

Studies have found that $\mathrm{Cd}$ toxicity could increase reactive oxygen species (ROS) and produce oxidative stress in plants, i.e., $\mathrm{H}_{2} \mathrm{O}_{2}$ and $\mathrm{O}_{2} .^{-}$(Wu et al., 2014). Overproduction of ROS might cause adverse effect on the growth, metabolism and development of cells through their ability to initiate reaction cascades that result in extensive lipid peroxidation as indicated by higher accumulation of MDA in chloroplasts of plants (Gossett et al., 1994). In our current study, treatment with $100 \mu M-\mathrm{CdCl}_{2}$ significantly increased $(P<0.05) \mathrm{H}_{2} \mathrm{O}_{2}, \mathrm{O}_{2}{ }^{-}$and MDA content in Jerusalem artichoke seedlings, implying that $\mathrm{Cd}$ stress caused increased ROS production, thus conduced to the damage of plasma membrane structure. Previous studies have found that REEs could protect plants against oxidative stress under various adverse conditions (Wang et al., 2009; Wang et al., 2011). In this experiment, Low concentration of $\mathrm{NdCl}_{3}(10 \mathrm{mM}$ and $20 \mu M)$ decrease production of $\mathrm{H}_{2} \mathrm{O}_{2}$, $\mathrm{O}_{2}{ }^{-}$and accumulation of MDA induced by $\mathrm{Cd}$ stress, suggesting that $\mathrm{NdCl}_{3}$ could directly remove ROS such as $\mathrm{H}_{2} \mathrm{O}_{2}$ and $\mathrm{O}_{2}{ }^{-}$and protect plasma membrane lipid against oxidative damage.

To protect themselves from oxidative damage in adverse environments, plants have developed complex antioxidant systems consisting of antioxidative enzymes including SOD, CAT and POD and antioxidant compounds (Zhao et al., 2008; Sharma and Dietz, 2009). In this paper, the activities of SOD and POD were significantly inhibited $(P<0.05)$ under $\mathrm{Cd}$ stress, implying that exposure to high salinity resulted in an imbalance between ROS and their removal in Jerusalem artichoke seedlings. Previous studies have shown that RE could affect the activities of many antioxidative enzymes and antioxidant compounds in plants to alleviate the injury of stress. It was reported that addition of $\mathrm{LaCl}_{3}$ increased the activities of SOD, ascorbate peroxidase (APOX), CAT and glutathione reductase (GR) in Saussurea involucrata under salt stress (Xu et al., 2008). The treatments of $\mathrm{LaCl}_{3}, \mathrm{NdCl}_{3}$ and $\mathrm{CeCl}_{3}$ significantly increase the activities of antioxidative enzyme in maize seedling under cold stress (Wang et al., 2011). In this experiment, compared with $\mathrm{CdCl}_{2}$ treatment, addition of $\mathrm{NdCl}_{3}(10 \mu M$ and $20 \mu M)$ could significantly increase $(P<0.05)$ the activities of SOD, CAT and POD in seedling under $\mathrm{Cd}$ stress, implying that $\mathrm{NdCl}_{3}$ could remarkedly enhance the capacity of antioxidant system against oxidative damage induced by $\mathrm{Cd}$ toxicity in Jerusalem artichoke.

In conclusion, the results from this study demonstrated that appropriate concentration $\mathrm{NdCl}_{3}$ could significantly stimulate the growth of Jerusalem artichoke alleviated the oxidative damage and increase the activities of SOD, POD and CAT enzymes under $\mathrm{Cd}$ stress. The future research should be focus on elucidating $\mathrm{NdCl}_{3}$ induced changes of these physiobiochemical processes at molecular and cellular level and discussing whether the $\mathrm{NdCl}_{3}$ has active action in the nonenzymatic reaction.

\section{Acknowledgment}

Authors would like to thank Science and Technology Department of Shandong Province (2010GSF10208) for financial support.

\section{References}

Ali, S., F. Zeng, S. Cai, B. Qiu and G.P. Zhang, 2011. The interaction of salinity and chromium in the influence of barley growth and oxidative stress. Plant Soil Environ., 57: 153-159

Atta Ullah, H., F. Javed, A. Wahid and B. Sadia, 2016. Alleviating effect of exogenous application of ascorbic acid on growth and mineral nutrients in cadmium stressed barley (Hordeum vulgare) seedlings. Int. J. Agric. Biol., 18: 73-79

Basharat, A., R.A. Gill, S. Yang, M.B. Gill, S. Ali, M.T. Rafiq and W Zhou. 2014. Hydrogen sulfide alleviates cadmium-induced morphophysiological and ultrastructural changes in Brassica napus. Ecotoxicol. Environ. Saf., 110: 197-207

Beauchamp, C. and I. Fridovich, 1971. Superoxide dismutase: Improved assays and assay applicable to acrylamide gels. Anal. Biochem., 44: 276-286

Buege, J.A. and S.D. Aust, 1978. Microsomal lipid peroxidation. Meth. Enzymol., 52: 302-310.

Durner, J. and D.F. Klessing, 1996. Salicy'lic acid is a modulator of tobacco and mammalian catalases. J. Biol. Chem., 271: 28492-28502

Elstner, E.F. and A. Heupel, 1976. Inhibition of nitrite formation from hydroxylammonium chloride: a simple assay for superoxide dismutase. Anal. Biochem., 70: 616-620 
Gallego, S.M., L.B. Pena, R.A. Barcia, C.E. Azpilicueta, M.F. Iannone and E.P. Rosales, 2012. Unravelling cadmium toxicity and tolerance in plants: insight into regulatory mechanisms. Environ. Exp. Bot., 83: 33-46

Gill, S.S. and N. Tuteja, 2010. Reactive oxygen species and antioxidant machinery in abiotic stress tolerance in crop plants. Plant Physiol. Biochem., 48: 909-930

Gossett, D.R., E.P. Millhollon and M.C. Lucas, 1994. Antioxidant response to $\mathrm{NaCl}$ stress in salt tolerant and salt sensitive cultivars of cotton. Crop Sci., 34: 706-714

Gowayed, S.M.H., H.S.M. Al-Zahrani and E.M.R. Metwali, 2017. Improving the salinity tolerance in potato (Solanum tuberosum) by exogenous application of silicon dioxide nanoparticles. Int. J. Agric. Biol., 19: 183-194

Hammerschmidt, R., E.M. Nuckles and J. Kuc, 1982. Association of enhanced peroxidase-activity with induced systemic resistance of cucumber to colletotrichum-lagenarium. Physiol. Plant Pathol., 20: $73-76$

Huang, Z., X.H. Long, J. Kang, Z. Zhang, R. Zed and Z.P. Liu, 2012. Growth, photosynthesis and $\mathrm{H}^{+}$-ATPase activity in two Jerusalem artichoke varieties under $\mathrm{NaCl}$-induced stress. Process Biochem., 47: 591-596

Hussain, I., M.A. Ashraf, R. Rasheed, M. Iqbal, M. Ibrahim, T. Zahid, S. Thind and F. Saeed, 2017. Cadmium-induced perturbations in growth, oxidative defense system, catalase gene expression and fruit quality in tomato. Int. J. Agric. Biol., 19: 61-68

Kosaric, N., G. Cosentino, A. Wieczorek and Z. Duvnjak, 1984. Jerusalem artichoke as an agricultural crop. Biomass, 5: 1-36

Long, X.H., S.K. Mehta and Z.P. Liu, 2008. Effect of $\mathrm{NO}_{3}{ }^{-} \mathrm{N}$ enrichment on seawater stress tolerance of Jerusalem artichoke (Helianthus tuberosus). Pedosphere, 18: 113-123

Monti, A., M.T. Amaducci and G. Venturi, 2005. Growth response, leaf gas exchange and fructans accumulation of Jerusalem artichoke (Helianthus tuberosus L.) as affected by different water regimes. Eur. J. Agron., 23: 136-145

Pandey, V., V. Dixit and R. Shyam, 2005. Antioxidative responses in relation to growth of mustard (Brassica junceacv. PusaJaikisan) plants exposed to hexavalent chromium. Chemosphere, 61: 40-47

Peng, X., J. Zhang, J.Y. He and L. Ding, 2013. Influence of rare earth elements on metabolism and related enzyme activity and isozyme expression in Tetrastigma hemsleyanum cell suspension cultures. Biol. Trace. Elem. Res., 152: 82-90

Qiu, B.Y., F.R. Zeng, S.G. Cai, X.J. Wu, S.I. Haider, F.B. Wu and G.P. Zhang, 2013. Alleviation of chromium toxicity in rice seedlings by applying exogenous glutathione. J. Plant Physiol., 170: 772-779
Sanita, D.T. and R. Gabbrielli, 1999. Response to cadmium in higher plants. J. Exp. Bot., 41: 105-130

Sharma, S.S. and K.J. Dietz, 2009. The relationship between metal toxicity and cellular redox imbalance. Trends Plant Sci., 14: 43-50

Tao, Y.M., Y.Z. Chen, Y.L. Liang, M.Y. Xu and X.M. Xu, 2007. Cadmium-induced membrane lipid peroxidation and changes in antioxidant enzyme activities and peroxidase isoforms in Jerusalem artichoke seedlings. J. Plant Physiol. Mol. Biol., 33: 301-308

Wang, L.H., X.H. Huang and Q. Zhou, 2009 Protective effect of rare earth against oxidative stress under ultraviolet-B radiation. Biol. Trace. Elem. Res., 128: 82-93

Wang, M., J.H. Zou, X.C. Duan, W.S. Jiang and D.H. Liu, 2007. Cadmium accumulation and its effects on metal uptake in maize (Zea mays L.). Bioresour. Technol., 98: 82-88

Wang, Y., M. Zhou, X.L. Gong, C. Liu, M.M. Hong, L. Wang and F.S. Hong, 2011. Influence of lanthanides on the antioxidative defense system in maize seedlings under cold stress. Biol. Trace Elem. Res., 142: 819-830

Wang, Y., H. Jin, S. Deng, Y. Chen and Y. Yu, 2011. Effects of neodymium on growth and physiological characteristics of Microcystis aeruginosa. J. Rare Earth., 29: 388-395

Wu, M., P.Y. Wang, L.G. Sun, J.J. Zhang, J. Yu, Y.W. Wang and G.X. Chen, 2014. Alleviation of cadmium toxicity by cerium in rice seedlings is related to improved photosynthesis, elevated antioxidant enzymes and decreased oxidative stress. Plant Growth. Regul., 74: $251-260$

Xue, Y.F. and Z.P. Liu, 2008. Antioxidant enzymes and physiological characteristics in two Jerusalem artichoke cultivars under salt stress. Russ. J. Plant Physiol., 55: 776-781

Zafar, S.N. and F. Javed, 2016. In vitro study of interactive effect of cadmium and salicylic acid on growth and biochemical parameters in tetra and hexaploid wheat. Int. J. Agric. Biol., 18: 671-676

Zhang, F.Q., H.X. Zhang, G.P. Wang, L.L. Xu and Z.G. Shen, 2009. Cadmium-induced accumulation of hydrogen peroxide in the leaf apoplast of Phaseolus aureus and Vicia sativa and the roles of different antioxidant enzymes. J. Hazard. Mater., 168: 76-84

Zhang, P.Y. and K.S. Chen, 2007. Inducement of salicylic acid in cucumber cotyledons by neodymium and lanthanum. J. Rare Earth., 25: 502507

Zhao, J., G.X. Shi and Q.H. Yuan, 2008. Polyamines content and physiological and biochemical responses to ladder concentration of nickel stress in Hydrocharis dubia (B1.) backer leaves. BioMetals, 21: $665-674$

(Received 17 May 2017; Accepted 03 July 2017) 